\title{
OCORRÊNCIA E FATORES DE RISCO ASSOCIADOS À IDENTIFICAÇÃO DA ANEMIA INFECCIOSA EQUINA EM EQUÍDEOS DE TRAÇÃO
}

\author{
NANCyleni Pinto Chaves ${ }^{1}$, Danilo Cutrim Bezerra ${ }^{2}$, Hamilton Pereira SAntos ${ }^{3}$, HÉlder de \\ Moraes Perreira ${ }^{3}$, Porfírio CANDANEdo Guerra ${ }^{3}$, ANa LÚCia ABreu Silva ${ }^{3}$ \\ ${ }^{1}$ Pós-graduanda da Rede Nordeste de Biotecnologia (RENORBIO), São Luis, MA, Brasil. \\ nancylenichaves@hotmail.com \\ ${ }^{2}$ Pós-graduando da Rede Norte de Biotecnologia (BIONORTE), São Luis, MA, Brasil \\ ${ }^{3}$ Professores Doutores da Universidade Estadual do Maranhão, São Luis, MA, Brasil
}

O objetivo do presente trabalho foi determinar a ocorrência e os fatores de risco associados à identificação da anemia infecciosa equina (AIE) em equídeos de tração na Cidade de São Luís - MA. Amostras de sangue de 154 equídeos apreendidos em vias públicas, pelo Setor de Apreensão de Animais de Tração da Secretaria Municipal de Urbanismo e Habitação, foram coletadas no período de abril a agosto de 2011. Foram analisadas as fichas de atendimento individual para a determinação dos fatores de risco associados a esta enfermidade. Dos animais analisados, 5,20\% (8/154) foram positivos. Dentre os fatores de risco avaliados, presença de insetos, permanência dos equídeos em aglomerações por mais de oito horas diárias, condição corporal, estado nutricional, uso repetido de uma mesma agulha entre diferentes equídeos, ocorrência de episódios febris, mucosas amareladas e ausência de conhecimento sobre AIE apresentaram significância estatística $(\mathrm{P}<0,05)$ associada à AIE. Os resultados do estudo indicaram que a ocorrência da AIE para equídeos de tração apreendidos na Cidade de São Luís - MA foi baixa. Mesmo assim há a necessidade da realização de diagnóstico sistemático e monitoramento dos animais, além da implantação de medidas de controle, realização de exames sorológicos e implementação da legislação vigente.

PALAVRAS-CHAVE: asinino, equino, IDGA, Maranhão, muar.

\section{OCCURRENCE AND RISK FACTORS ASSOCIATED WITH IDENTIFICATION OF EQUINE INFECTIOUS ANEMIA IN TRACTION EQUIDAE}

\section{ABSTRACT}

The objective of this study was to determine the occurrence and risk factors associated with the identification of equine infectious anemia (EIA) in traction equines in the city of São Luiz - MA. We collected blood samples from 154 equines seized on public roads by the Sector of Animal Traction Seizure of the Municipal Urban Development and Housing Department between April and August of 2011. We analyzed the medical records to determine the individual risk factors associated with this disease. Of the animals tested, $5.20 \%(8 / 154)$ were positive. Among the risk factors evaluated, the presence of insects, permanence of the animals in agglomerations for longer than 8 hours per day, body condition, nutritional status, repeated use of the same needle among different equines, occurrence of febrile episodes, yellowish mucous and lack of knowledge 
on IEA showed to be statistically significant $(\mathrm{P}<0.05)$ associated with the IEA. The study results indicate that the occurrence of the IEA in traction equines in the City of São Luiz - MA was low. Still there is the necessity of

KEYWORDS: asinine, horse, IDGA, Maranhão, mules.

\section{INTRODUÇÃO}

A equideocultura constitui uma importante cadeia do agronegócio brasileiro ${ }^{1}$. As atividades que envolvem equídeos ganham importância, pois representam, para o Brasil, uma movimentação econômica na ordem de $\mathrm{R} \$ 7,3$ bilhões por ano e a ocupação direta de aproximadamente $640 \mathrm{mil}$ pessoas, que poderia atingir o valor de 3,2 milhões se fossem formalizados os empregos considerados indiretos ${ }^{2,3}$.

Segundo dados do Instituto Brasileiro de Geografia e Estatística de 2011, o rebanho equídeo brasileiro é de 8.322.551 animais, dos quais 2.937.224 pertencem à Região Nordeste. Deste total, 381.554 equídeos se encontram no Estado do Maranhão, sendo 171.942 equinos, 110.916 asininos e 98.696 muares $^{4}$.

Nas últimas quatro décadas, o equídeo tem se tornado importante para as pessoas, podendo ser um parceiro nas atividades esportivas e até proporcionar suporte financeiro. Nos grandes centros urbanos, por exemplo, uma das atividades que mais cresce é a utilização de equídeos de tração para o recolhimento do lixo produzido. Logo, o animal de tração surge como uma ferramenta de trabalho, cuja saúde e bem-estar devem ser observados ${ }^{5,6}$.

Na cidade de São Luís - MA, os equídeos são usados em veículos de tração animal, para transporte de material de construção, coleta de lixo e distribuição de água em áreas carentes da cidade, estando em contato direto com possíveis fontes de contaminação, favorecendo o risco de ocorrência de doenças infecciosas ${ }^{7}$. Entretanto, apesar da importância desta atividade, programas de sanidade animal que contemplem a erradicação de doenças infecciosas, a exemplo da Anemia Infecciosa Equina (AIE) são negligenciados.

A AIE, enfermidade que acomete equinos, muares e asininos, é causada pelo Vírus da Anemia Infecciosa Equina (VAIE), um Lentivírus da família Retroviridae. A AIE é uma infecção persistente, resultando em episódios periódicos de febre, anemia, hemorragias, entre outros sinais clínicos. Até o momento, é uma doença incurável e a legislação vigente preconiza o sacrifício $^{8}$, systematic diagnosis and monitoring of animals, as well as employment of control measures, serological tests and implementation of current legislation.

embora, para algumas regiões com alta prevalência, os pesquisadores indiquem a segregação dos animais soropositivos ${ }^{9}$.

O VAIE é transmitido mecanicamente por insetos hematófagos, sobretudo espécies de Tabanus sp. (mosca do cavalo) e Stomoxys calcitrans (mosca do estábulo). A AIE é, atualmente, um grande obstáculo para o desenvolvimento da equideocultura, por ser uma doença transmissível e incurável, acarretando prejuízos aos proprietários que necessitam do trabalho desses animais e aos criadores interessados na melhoria das raças, além de impedir o acesso ao mercado internacional ${ }^{1,10,11}$.

As estatísticas oficiais apresentam um perfil da situação epidemiológica da AIE, porém não informam, com exatidão, a taxa de prevalência da enfermidade no Brasil, uma vez que se referem, exclusivamente, aos exames laboratoriais realizados para trânsito interestadual e/ou participação em eventos agropecuários controlados pelos serviços oficiais de defesa sanitária animal. A maior parte do efetivo equídeo testado pertence a rebanhos de alto valor zootécnico em que a doença está controlada e, muitas vezes, o mesmo animal é testado mais de uma vez durante um curto período ${ }^{1}$.

A AIE não tem tratamento nem vacina eficaz; portanto, o seu controle é feito por meio do diagnóstico laboratorial, que é de fundamental importância para detecção dos portadores da doença ${ }^{8}$.

A identificação de fatores de risco associados à AIE é importante para auxiliar a planificação de uma política sanitária adequada para o controle e futura erradicação da enfermidade. Neste contexto, o objetivo desta pesquisa foi determinar a ocorrência e os fatores de risco associados à identificação da anemia infecciosa equina em equídeos de tração na Cidade de São Luís - MA.

\section{MATERIAL E MÉTODOS}

Este estudo foi desenvolvido na Cidade de São Luís, Estado do Maranhão, onde prevalecem as características fisiográficas da Região 
Amazônica. A região está subordinada ao clima quente-úmido de transição entre o superúmido amazônico e o semiárido nordestino, com seis meses chuvosos ${ }^{4}$. A pesquisa foi aprovada pela Comissão de Ética na Experimentação Animal CEEA do curso de Medicina Veterinária da Universidade Estadual do Maranhão, protocolo $\mathrm{n}^{\circ}$ 036/2011.

Foram utilizados, neste estudo, 154 equídeos de tração, entre machos e fêmeas, com idade superior a 24 meses, apreendidos em vias públicas, pelo Setor de Apreensão de Animais de Tração da Secretaria Municipal de Urbanismo e Habitação (SEMURH), no período de abril a agosto de 2011.

A colheita de sangue foi realizada por meio de punção da veia jugular utilizando-se agulha descartável estéril e tubo com vácuo, previamente identificado. As amostras de soro obtidas foram armazenadas em microtubos de plástico e congeladas a $-20^{\circ} \mathrm{C}$.

Foram utilizadas as fichas de atendimento individual da SEMURH que continham informações sobre as condições de criação e trabalho dos mesmos, manejo nutricional e sanitário. Algumas informações eram anotadas in locu no momento da apreensão dos animais (informações inerentes aos animais) e as demais quando o proprietário comparecia à SEMURH.

As variáveis relacionadas nas fichas de atendimento individual permitiram o estudo dos fatores de risco. Dentre elas, foram analisadas como possíveis fatores de risco: presença de insetos, permanência dos equídeos em aglomerações por mais de 8 horas diárias, condição corporal, estado nutricional, utilização comum de apetrechos de montaria, uso repetido de uma mesma agulha entre diferentes equídeos, ocorrência de episódios febris, mucosas amareladas e conhecimento dos proprietários sobre AIE.

O diagnóstico da enfermidade foi realizado pela técnica de Imunodifusão em Gel de Ágar, segundo Nakajima e Ushimi ${ }^{12}$, em um laboratório particular da Cidade de São Luís - MA, credenciado no Ministério da Agricultura, Pecuária e Abastecimento (MAPA).

Foi calculada a ocorrência total de animais positivos bem como as ocorrências segundo a espécie animal acometida. Para o estudo da associação entre a soropositividade e as variáveis analisadas, foi feita a análise univariada, utilizando-se o teste Exato de Fisher. O nível de significância utilizado foi de $5 \%$, com intervalos de confiabilidade de $95 \%$.

\section{RESULTADOS E DISCUSSÃO}

Do total de amostras analisadas, 144 eram de asininos, oito de equinos e duas de muares. Segundo Chaves et al. ${ }^{6}$, na Cidade de São Luís MA, a atividade de tração é desenvolvida em maior percentual pela espécie asinina, o que condiz com o maior percentual de asininos apreendidos no período do estudo. Os resultados laboratoriais por espécie animal encontram-se discriminados na Tabela 1.

Tabela 1. Resultados laboratoriais para Anemia Infecciosa Equina (AIE) em 154 amostras séricas de equídeos de tração apreendidos na Cidade de São Luís - MA, 2011

\begin{tabular}{lcccccc}
\hline & \multicolumn{5}{c}{ Diagnóstico Laboratorial } \\
\cline { 2 - 7 } Espécie Animal & \multicolumn{2}{c}{ Positivos } & \multicolumn{2}{c}{ Negativos } & \multicolumn{2}{c}{ Total } \\
& $\mathrm{N}$ & $\%$ & $\mathrm{~N}$ & $\%$ & $\mathrm{n}$ & $\%$ \\
\hline Asinina & 3 & 1,94 & 141 & 91,56 & 144 & 93,50 \\
Equina & 4 & 2,60 & 4 & 2,60 & 8 & 5,20 \\
Muar & 1 & 0,65 & 1 & 0,65 & 2 & 1,30 \\
Total & 8 & 5,20 & 146 & 94,80 & 154 & 100 \\
\hline
\end{tabular}

Foi observada ocorrência total de 5,20\% (8/154) de AIE. Para as espécies asinina e equina e para os muares foram verificadas ocorrências de $1,94 \%, 2,60 \%$ e $0,65 \%$, respectivamente. Apesar dos baixos valores encontrados em relação ao total, estes se assemelham aos de outros estudos realizados no país $^{1}$ e indicam que o Vírus da Anemia Infecciosa Equina (VAIE) está circulando na população equídea 
de tração cujos exemplares foram apreendidos na Cidade de São Luís - MA. Quando os valores de ocorrência da AIE foram avaliados separadamente, por espécie, observaram-se valores elevados para os equinos $(50 \% ; 4 / 8)$ e muares $(50 \% ; 1 / 2)$ e baixos valores para os asininos $(2,12 \% ; 3 / 144)$, o que sugere maior resistência da última espécie para a enfermidade em questão.
$\mathrm{O}$ risco de transmissão da AIE entre animais positivos e sadios aumenta com a proximidade destes. Desta forma, os animais positivos identificados no estudo configuram-se como potencial fonte de infecção para animais susceptíveis. As variáveis analisadas como prováveis fatores de risco associados à identificação da AIE podem ser observadas na Tabela 2 .

Tabela 2. Fatores de risco para a identificação da anemia infecciosa equina em equídeos de tração apreendidos na Cidade de São Luís - MA, 2011

\begin{tabular}{|c|c|c|c|c|c|c|c|c|c|c|}
\hline \multirow{3}{*}{ Variáveis } & & \multicolumn{9}{|c|}{ Anemia Infecciosa Equina - AIE } \\
\hline & & \multicolumn{2}{|c|}{ Positivos } & \multicolumn{2}{|c|}{ Negativos } & \multicolumn{2}{|c|}{ Total } & \multirow{2}{*}{ OR } & \multirow{2}{*}{ IC $95 \%$} & \multirow{2}{*}{ Valor de $\mathrm{P}$} \\
\hline & & $\mathrm{N}$ & $\%$ & $\mathrm{~N}$ & $\%$ & $\mathrm{~N}$ & $\%$ & & & \\
\hline \multirow{2}{*}{ Presença de insetos } & Sim & 7 & 5 & 60 & 39 & 67 & 44 & \multirow{2}{*}{10,03} & \multirow{2}{*}{1,$202 ; 83,722$} & \multirow{2}{*}{0,02} \\
\hline & Não & 1 & 1 & 86 & 56 & 87 & 56 & & & \\
\hline \multirow{2}{*}{$\begin{array}{l}\text { Permanência em aglomerações } \\
\text { por mais de } 8 \text { horas diárias }\end{array}$} & Sim & 8 & 5 & 50 & 32 & 58 & 37 & \multirow{2}{*}{32,48} & \multirow{2}{*}{1,$836 ; 574,73$} & \multirow{2}{*}{0,00} \\
\hline & Não & 0 & 0 & 96 & 62 & 96 & 62 & & & \\
\hline \multirow[b]{2}{*}{ Condição Corporal } & Satisfatória & 2 & 1 & 124 & 81 & 126 & 82 & \multirow{2}{*}{0,05} & \multirow{2}{*}{0,$011 ; 0,312$} & \multirow{2}{*}{0,00} \\
\hline & Insatisfatório & 6 & 4 & 22 & 14 & 28 & 18 & & & \\
\hline \multirow{2}{*}{ Estado Nutricional } & Satisfatório & 2 & 1 & 124 & 81 & 126 & 82 & \multirow{2}{*}{0,05} & \multirow{2}{*}{0,$011 ; 0,312$} & \multirow{2}{*}{0,00} \\
\hline & Insatisfatório & 6 & 4 & 22 & 14 & 28 & 18 & & & \\
\hline \multirow{2}{*}{$\begin{array}{l}\text { Utilização comum de apetrechos } \\
\text { de montaria }\end{array}$} & Sim & 4 & 3 & 96 & 62 & 100 & 65 & \multirow{2}{*}{0,52} & \multirow{2}{*}{0,$124 ; 2,172$} & \multirow{2}{*}{0,45} \\
\hline & Não & 4 & 3 & 50 & 32 & 54 & 35 & & & \\
\hline \multirow{2}{*}{ Uso repetido da mesma agulha } & Sim & 7 & 5 & 40 & 26 & 47 & 31 & \multirow{2}{*}{18,55} & \multirow{2}{*}{2,$211 ; 155,650$} & \multirow{2}{*}{0,00} \\
\hline & Não & 1 & 1 & 106 & 69 & 107 & 69 & & & \\
\hline \multirow{2}{*}{ Episódios febris } & Sim & 6 & 4 & 40 & 26 & 46 & 30 & 7.95 & 1,$540 ; 41,046$ & 0,00 \\
\hline & Não & 2 & 1 & 106 & 69 & 108 & 70 & & & \\
\hline Mucos & Sim & 6 & 4 & 40 & 26 & 46 & 30 & 7,95 & 1,$540 ; 41,046$ & 0,00 \\
\hline & Não & 2 & 1 & 106 & 69 & 108 & 70 & & & \\
\hline hecimento da AIE & Sim & 3 & 2 & 121 & 79 & 124 & 81 & 0,12 & 0,$0278 ; 0,552$ & 0,00 \\
\hline & Não & 5 & 3 & 25 & 16 & 30 & 19 & & & \\
\hline
\end{tabular}

A diversidade e abundância dos vetores (insetos hematófagos) são fatores que podem influenciar a transmissão do VAIE, particularmente associadas com o estado clínico e quantidade do vírus no sangue dos equídeos infectados ${ }^{10,13}$. Neste estudo, a variável presença de insetos relatada em $44 \%$ dos animais apresentou associação estatística significativa $(\mathrm{P}<0,05)$ ao risco de ocorrência da AIE para equídeos de tração apreendidos.

A Cidade de São Luís - MA apresenta características geoclimáticas ${ }^{4}$ favoráveis à proliferação de tabanídeos. Associados a isso, o crescimento urbano desordenado e a grande quantidade de lixo espalhada sobre vias e terrenos baldios propiciam um ambiente ideal para a proliferação de insetos-vetores. Segundo informações obtidas na ficha de avaliação individual, os equídeos são criados em bairros da cidade com condições sanitárias e de infra-estrutura precárias.

Não existem métodos práticos e eficazes para o controle dos vetores. O risco de transmissão mecânica por esses insetos pode apenas ser minimizado separando-se animais positivos dos negativos. No Pantanal - MS, estudos sobre o 
deslocamento de tabanídeos entre animais positivos e negativos indicam que o distanciamento mínimo de 50 metros entre eles propicia uma adequada margem de segurança com relação ao risco de transmissão do VAIE por esses vetores ${ }^{14}$.

A atividade de tração animal na Cidade de São Luís - MA é realizada, principalmente, em locais onde predomina o comércio de material de construção, coleta de lixo e distribuição de água em áreas carentes da cidade ${ }^{7}$. Nesses locais, os animais são mantidos em aglomerações, por pelo menos oito horas diárias, à espera de frete (carga), conforme identificado em $37 \%$ dos casos. As condições higiênicas desses locais também podem propiciar a existência de vetores. Esta variável esteve associada $(\mathrm{P}<0,05)$ ao risco de ocorrência da AIE nos animais avaliados.

Os animais de tração são submetidos diariamente a transporte de material com carga que ultrapassa $500 \mathrm{Kg}$ e apresentam manejo alimentar e score corporal incompatíveis com a atividade exercida. Dos animais apreendidos, 30\% (46/154) apresentaram episódios febris, perda de peso, debilidade progressiva, mucosas amareladas e edemas subcutâneos. As variáveis condição corporal, estado nutricional, episódios febris e mucosas amareladas apresentaram associação estatística significativa $(\mathrm{P}<0,05)$ para a ocorrência desta enfermidade. SOUSA et al. ${ }^{15}$ relataram que animais ficam suscetíveis à AIE quando têm resistência orgânica diminuída por trabalho excessivo, calor intenso, alimentação inadequada e infestação por parasitas, situações averiguadas neste estudo.

A exposição de animais susceptíveis a utensílios previamente contaminados é particularmente importante na transmissão do VAIE $^{13}$. A utilização comum de apetrechos de montaria e de agulhas quando da aplicação de medicamentos foram aspectos relatados pelos proprietários em $\quad 65 \%$ e $35 \%$ dos casos, respectivamente. Entretanto, apenas a variável utilização comum de apetrechos de montaria não apresentou associação estatística significativa $(\mathrm{P}>0,05)$ para a ocorrência da enfermidade em equídeos de tração neste estudo. Talvez esta variável tenha maior relevância para animais que desempenham atividades esportivas, como a montaria.

Foi observada desinformação dos proprietários quanto a AIE (19\%) e, associação estatística desta variável com a ocorrência da doença. Entre os criadores, não há a preocupação em sacrificar os animais portadores, quando identificados, e tampouco em promover o saneamento da área.

A AIE é uma das doenças mais importantes em equídeos do ponto de vista sanitário e econômico. Dessa forma, torna-se necessário aperfeiçoar os recursos de manejo sanitário e de diagnóstico, uma vez que, de acordo com a legislação vigente, os animais soropositivos devem ser eutanasiados ${ }^{8}$, representando alto custo para a reposição dos animais.

Os resultados obtidos são importantes para alertar sobre a necessidade de direcionamento e priorização do plano de controle da enfermidade no Estado do Maranhão, ajustando-o à epidemiologia da doença e à realidade sócio-econômica da área de estudo e dos proprietários dos animais. Adicionalmente, é importante implantar um programa de educação sanitária específico para o público que lida no dia-a-dia com os animais e universalizar o acesso dos proprietários ao exame de diagnóstico oficial. Além disso, também é importante realizar estudos sobre a ecologia dos vetores para identificação das espécies de tabanídeos presentes no Estado, determinar sua sazonalidade e a abundância nos diferentes habitats.

\section{CONCLUSÕES}

Os resultados obtidos nesta pesquisa, considerando-se a análise e interpretação dos aspectos sanitários da AIE, permitiram concluir que a ocorrência do vírus da AIE foi baixa. Os fatores de risco associados à identificação da enfermidade foram: presença de insetos, permanência dos equídeos em aglomerações por mais de 8 horas diárias, condição corporal insatisfatória, estado nutricional insatisfatório, uso repetido de uma mesma agulha entre diferentes equídeos, ocorrência de episódios febris, mucosas amareladas e ausência de conhecimento sobre AIE.

\section{AGRADECIMENTOS}

À Secretaria Municipal de Urbanismo e Habitação (SEMURH), pela concessão dos dados necessários para a realização do estudo dos fatores de risco.

\section{REFERÊNCIAS}

1. Almeida V M A, Gonçalves V S P, Martins M F, Haddad J P A, Dias R A, Leite R C, Reis J K P. Anemia infecciosa equina: prevalência em equídeos de serviço em Minas Gerais. Arquivo Brasileiro de Medicina Veterinária e Zootecnia. 2006; 58(2): 141-148. Disponível em: http://www.scielo.br/scielo.php?pid=S0102$09352006000200001 \&$ script=sci_arttext. Português.

2. CNA. Estudo do complexo agronegócio do cavalo. 
2004.

Disponível

em:

$<$ http://www.cepea.esalq.usp.br/pdf/cavalo_resumo.pdf $>$.

Acesso em: 17 de Mar. de 2012.

3. Karam C H V, Rolim M F, Graça F A S, Aragão A P. Anemia infecciosa equina no estado do Rio de Janeiro: aspectos epidemiológicos, clínicos e laboratoriais. Revista Eletrônica Novo Enfoque. 2010; 09(09): 01-13. Disponível em: http://www.castelobranco.br/sistema/novoenfoque/files/09 /artigos/01.pdf. Português.

4. IBGE. Instituto Brasileiro de Geografia e Estatística, 2011. Disponível em: http://www.ibge.gov.com.br. Acesso em: 17 de Mar. de 2012.

5. Maranhão R P A, Palhares M S, Melo U P, Rezende $H$ H C, Ferreira, C. Avaliação biométrica do equilíbrio podal de equídeos de tração no município de Belo Horizonte. Ciência Animal Brasileira. 2007; 8(2): 297-305. Disponível em: http://www.revistas.ufg.br/index.php/vet/article/view/135 4/1410. Português.

6. Chaves N P, Bezerra D C, Guerra P C, Pereira H de M, Santos H P, Vulcano L C. Lesões Podais em Asininos (Equus Asinus) utilizados em veículos de tração animal na cidade de São Luís, Maranhão. Ciência Animal Brasileira. 2011; 12(2): 365-370. Disponível em: http://dx.doi.org/ 1 0.521 6/cab.v1 2i2.8953.

7. Bezerra D C, Chaves N P, Guerra P C, Pereira H de M, Santos H P. Pesquisa de aglutininas antileptospira em soros sanguíneos de asininos (Equus asinus) e de condutores de veículos de tração animal na cidade de São Luís, MA, Brasil. Ciência Animal Brasileira. 2010; 11(4): 931-937. Disponível em: http://dx.doi.org/10.5216/cab.v11i4.9233.

8. Brasil. Instrução Normativa Número 45, de 15 de junho de 2004, da Secretaria de Defesa Agropecuária do Ministério da Agricultura, Pecuária e Abastecimento. Disponível em:
$<$ http://extranet.agricultura.gov.br/sislegisconsulta/consult arLegislacao.do?operacao=visualizar\&id $=8136>$. Acesso em: 15 de Mar. de 2012. Portiguese.

9. Silva R A M S, Abreu U G P, Barros A T M. Anemia Infecciosa Equina: Epizootiologia, prevenção e controle. [Internet] Embrapa Pantanal. Circular Técnica. 2001; 29: 7-18.Disponível em http://ainfo.cnptia.embrapa.br/digital/bitstream/item/3756 8/1/CT29.pdf. Português

10. Van Regenmortel M H, Mayo M A, Fauquet C M, Manillof J. Virus nomenclature: consensus versus chaos. Archives of Virology. 2000; 145: 2227-2232.

11. Maidana N. A, Bassanezi R C. Modelagem da dinâmica da anemia infecciosa equina. Biomatemática. 2011; 21: 87-102. Disponível em: http://www.ime.unicamp.br/ biomat/bio21 art7.pdf. Português

12. Nakajima H, Ushimi C. Immunodiffusion studies of purified equine infectious anemia virus. Infection and Immunity. 1971; 3: 373-377.

13. Issel C J, Mcmanus J M, Hagius S D, Foil L D, Adams W V Jr, Montelaro R C. Equine infectious anemia: prospects for control. Developments in Biological Standartization, Basel. 1990; 72: 49-57.

14. Barros A T M, Foil L D. Influência da distância na transferência de tabanídeos (Diptera: Tabanidae) entre equinos. Embrapa Pantanal, Boletim de Pesquisa e Desenvolvimento, 92, 2009, 15p. [Internet] citado em 26 agosto de 2014, disponível em http://www.cpap.embrapa.br/publicacoes/online/BP92.pdf

15. Souza A O, Salvatti J R Jr, Piccinin A. Anemia Infecciosa Equina. Revista Científica Eletrônica de Medicina Veterinária. 2008; 10. Disponível em: p://api.ning.com/files/ufBwcNx0JhFrG7UTleDM9oHgOr QJt54DL3Y07nE3ksDkYhsPvYS4DV2HsqiV2pZ5XQXa ts9SMX6v1G1BL09H2QsDwIzOeXSC/Anemiainfecciosa equina.pdf. 